\title{
La "fusión de horizontes" de Gadamer para la Historia de las Mujeres y de Género CON BASE EN LA NOCIÓN DE LA HISTORIA DE JOHN GADDIS
}

\author{
CAmila NeVES GuZmáN \\ Universidad de Concepción \\ Concepción | Chile \\ cneves@udec.cl \\ orcid.org/0000-0003-3814-8521
}

Este trabajo pretende mostrar que la "fusión de horizontes" de Gadamer y la idea de la historia de Gaddis permiten establecer una cercanía consciente entre las historiadoras de mujeres y de género con su pasado para democratizar los espacios de reflexión histórica. Es posible inferir que la integración de la categoría de género a los estudios de mujeres ha contribuido a la adopción de un compromiso político que justifica el nexo entre la teoría y la práctica en la producción historiográfica, lo cual, a su vez, posibilitó revelar el rol de las mujeres, otorgándole una complejidad a la comprensión de su histórica lucha por deconstruir la conflictividad binaria hombre/mujer.

Representación histórica - Fusión de horizontes Historia de las mujeres y de género

\footnotetext{
Este trabajo ha sido apoyado financieramente por la Agencia Nacional de Investigación y Desarrollo (ANID) a través de ANID-

PFCHA/Doctorado Nacional/ 2020-21201046
} 


\title{
Gadamer's "fusion of borizons" for the History of Women and the Gender
}

\section{BASED ON THE UNDERSTANDING OF HISTORY OF JOHN GADDIS}

\author{
Camila NeVES GuZmáN \\ Universidad de Concepción \\ Concepción | Chile \\ cneves@udec.cl \\ orcid.org/0000-0003-3814-8521
}

\begin{abstract}
This work aims to show that Gadamer's "fusion of horizons" and Gaddis's idea of history allow for a conscious closeness between women and gender historians with their past in order to democratize spaces for historical reflection. It is possible to infer that the integration of the gender category into women's studies has contributed to the adoption of a political commitment that justifies the nexus between theory and practice in historiographic production, which, in turn, made possible to reveal the role of women, giving complexity to the understanding of their historical struggle to deconstruct the binary male/female conflict.
\end{abstract}

bistorical representation - fusion of horizons history of women and the gender 


\section{INTRODUCCIÓN}

Los estudios de mujeres y género han mostrado la evidente conexión entre teoría y política, cuya relevancia ha desafiado las aspiraciones de verdad universal por parte de una historiografía androcéntrica (Smith 2003, 31; Scott 1996, 78-79). Por tanto, estas áreas abren un abanico amplio de problemas históricos de los cuales emergen reflexiones que se ajustan a las problemáticas políticas actuales a partir de un diálogo sostenido con el pasado. Lo anterior, a partir del punto de vista que ha introducido el investigador en la indagación histórica al sumergirse en las perspectivas hermenéutica y simbólica, logrando obtener resonancia en el presente la experiencia de las mujeres del pasado a partir de un diálogo constante entre lo pretérito y lo contemporáneo (Castañeda 2010, 231).

La historia de las mujeres, originariamente ligada al activismo político, surge a partir del estallido de la segunda ola feminista del siglo XX (Scott 1996, 60). Desde sus inicios, tuvo el fin de visibilizar a las mujeres en una "historia contributivista" al alero de la nueva historia (Valobra 2005, 103). Por ende, este campo de estudio contiene un análisis político asociado al movimiento feminista (Scott 1996, 61). Por su parte, la historia de género se comienza a desarrollar desde la década de 1990, introduciendo nuevos estudios relacionados con los movimientos sociales de mujeres, feministas, gays y lesbianas (Pedro 2005, 78). Su variedad temática se desarrolla en torno a perspectivas relacionadas con la cuestión del cuerpo, el multiculturalismo, la hegemonía y las políticas públicas (Valobra 2005, 104). Ello, en relación con las diferenciadas experiencias de mujeres reunidas en una esencia femenina en perspectiva histórica (Scott 1996, 80). Por su parte, los estudios de género han surgido a la luz de la teoría posestructuralista (Butler 2007, 9). Para Scott $(2008,20)$ el género significó el conocimiento de la diferencia sexual. Esto, desde una revisión crítica, ha permitido rescatar lo silenciado e ignorado introduciendo nuevas teorías. De esta manera, estudios sobre la dominación masculina, la subordinación histórica de las mujeres, la homosexualidad y la transexualidad, han aportado reflexiones sobre la necesidad de pensar en una sociedad andrógina y sin género (Rubin 2013, 85; Butler 2007, 13; García-Peña 2016; Bartra 2010, 75).

Variados autores le han otorgado historicidad al desarrollo de la historia de las mujeres y, por otro lado, a la historia de las relaciones de género. Estas investigaciones han procurado mostrar cómo la profesionalización de la historia de las mujeres y de género otorgaron plasticidad a la ciencia historiográfica a partir de sus reflexiones y análisis sobre las subalternidades sexuales en confrontación con la hegemonía falogocéntrica. Por una parte, existe una literatura enfocada en los desafíos a los que se ha enfrentado en las últimas décadas la introducción del estudio de mujeres y género en diversas dimensiones de la historia. Valobra $(2005,122)$ explica el recorrido académico de la historia de género y de las mujeres comprendiendo sus aportes, problemas comunes y desafíos relacionados con el ejercicio solidario en contra de las raíces androcéntricas en el círculo de la academia. También, Ríos $(2010,186)$ señala cómo la historia de las mujeres ha pretendido mostrar, en su desarrollo intelectual, la tensión hacia una sociedad emancipada y justa. Igualmente, se ha analizado la importancia de la introducción de conceptos relacionados con el género y lo femenino. Pedro $(2005,77)$ otorga historicidad a las categorías de análisis como "mujer", "mujeres", "género" y "sexo", aplicadas al estudio de la historia de los movimientos sociales de mujeres, feministas, gays y lesbianas en un contexto de lucha por los derechos civiles. Sin embargo, Scott $(2012,347)$ 
aclara que el uso de la categoría de género ha dado lugar a intensos debates, aunque ha abierto el camino a nuevas interpretaciones. Dauphin $(2001,17)$ agrega que tales categorías han aportado nuevo conocimiento sobre la dominación masculina, la subalternidad y su desventajosa relación en el acontecer histórico. Por otro lado, también se han desarrollado estudios sobre el aporte de la Historia social en el surgimiento y desarrollo de estas áreas de la historia. Scott $(1996,80)$, Tilly $(1994,35)$ y Philainen $(2019,140)$ destacan cómo ambos campos de estudio han surgido a partir de un análisis crítico de la hegemonía científica androcéntrica basándose, a partir de la historia social, en la deconstrucción y el desarrollo de un escrito posicionado políticamente, articulando a la historia con la ideología. De esta manera, la historia social aportó a la historia de las mujeres y de género la comprensión diferida de la experiencia de mujeres y minorías sexuales. A partir de tales estudios, es posible recalcar que el quiebre intelectual de finales del siglo XX ha permitido una flexibilidad histórica a la luz de la Nueva Historia.

Lo anterior, ha permitido una proliferación de estudio de mujeres y, posteriormente, estudios de género que proporcionan profundos análisis y heterogéneas temáticas y, a su vez, desafían los pilares de una ciencia historiográfica androcéntrica. Sin embargo, literatura sobre la historicidad contemporánea de la historia de las mujeres y de género desde una perspectiva hermenéutica no se ha tratado concretamente, por lo que este artículo pretende otorgar una nueva mirada sobre el desarrollo actual de estos campos de estudio.

El presente artículo pone énfasis en los estudios de mujeres acompañados de una perspectiva de género. Desde tal enfoque, este trabajo pretende estudiar cómo la idea de la historia de John Gaddis y "la fusión de horizontes" de Hans-Georg Gadamer aportan una herramienta hermenéutica esencial como base para el desarrollo de la historia de las mujeres y de las relaciones género. Tal contribución ha dispuesto una práctica investigativa definida por la cercanía consciente entre el historiador y su pasado que lograría aterrizar la ciencia histórica al compromiso político de la equidad de género en el círculo académico y en el conocimiento histórico a partir de la introducción de la categoría de género a los estudios de mujeres. Lo anterior, otorga respuestas a la lucha por democratizar los espacios de reflexión científicos y visibilizar la importancia de la mujer y las subalternidades en el acontecer histórico, comprendiendo tal lucha como producto de una tradición que envuelve a la disciplina histórica en un espacio en común del cual devienen reflexiones con sus múltiples complejidades.

Este trabajo, en primer lugar, rescata cómo la hermenéutica gadameriana y la idea de la historia de Gaddis sintetizan la cercanía entre el pasado y el presente en el estudio histórico y de qué manera impactan en los estudios de mujeres a partir de herramientas lingüísticas que rescatan el aporte femenino a la historia. En segundo lugar, muestra cómo el intercambio de miradas historiográficas y la interdisciplina han aportado a la relación entre la teoría y la praxis, es decir, entre la historia de las mujeres y/o de género y el movimiento feminista respecto al valor de la diferencia frente a la "verdad universal" a partir de la categoría de género. En tercer lugar, estudia cómo la relación pasadopresente-futuro de la hermenéutica gadameriana en la ciencia histórica ha permitido la identificación de las historiadoras con su pasado homónimo, a partir de la cual se han establecido desafíos a futuro relacionados con la construcción de espacios democráticos en los círculos académicos. En último y cuarto lugar, comprende el señorío del investigador con el pasado como forma de oposición ante la "verdad única" falogocéntrica y, por otro lado, la humildad que 
compromete a las investigadoras con la lucha feminista al bucear en la memoria de las mujeres.

\section{EL LENGUAJE UNIVERSAL EN EL "ESPEJO DEL PASADO" Y EL NEXO CON EL HORIZONTE DEL PASADO PARA LA COMPRENSIÓN DE SÍ MISMO}

John Gaddis, en su obra El paisaje de la historia, cómo los historiadores representan el pasado, explica la forma en que el historiador elabora representaciones históricas en su relación con el pasado. Para ello, presenta una analogía a partir de la obra de Caspar David Friedrich El caminante ante un mar de niebla para mostrar cómo sus elementos iconográficos simbolizan las herramientas y métodos investigativos del historiador al estudiar el pasado, quien se ve reflejado en el explorador de este paisaje nuboso (Oviedo 2017, 215). Por otro lado, Gadamer, desde el dasein heideggeriano, replantea la hermenéutica a partir de la comprensión del "ser en el mundo" y de la mediación del pensamiento con la vida actual (De la Maza 2005, 132; Vásquez 1992, 170). Estos aspectos constituyen la "fusión de horizontes", definida como un encuentro entre tradiciones donde el historiador interpreta el pasado a partir de su experiencia cultural mediada por el lenguaje que conforma, de igual manera, el horizonte pretérito (Vásquez 1992, 172). De esta manera, se entremezclan los horizontes a partir de la continuidad de una conversación (Gadamer 1998, 63).

La conjunción de ambas ópticas, respecto al estudio del pasado, sintetiza la relación estrecha entre el historiador y los sujetos del pasado a través del análisis documental: la cercanía construida en el proceso investigativo entre pasado y presente establece un espacio de diálogo sostenido entre distintas llanuras u horizontes. Esta situación hermenéutica permite el encuentro entre distintos puntos de vista que pueden aportar al debate enriquecedor para responder al compromiso social desde la historia. Tal forma de estudiar el pasado ha sido revisada por la historiadora Bonnie Smith $(2003,15)$, metaforizándola como el "espejo de la historia". La autora señala que a través de este espejo no sólo podemos observar los cambios y movimientos del pasado, sino que también se logra la autocomprensión y la construcción de una mentalidad científica sin prejuicios. Dichas prácticas y herramientas que otorgan tal espejo permiten obtener una relación dialéctica entre el pasado y nuestro presente.

La niebla que aparece en la obra de Caspar David Friedrich, para Gaddis $(2004,17)$, representa la extrañeza del pasado que se manifiesta en el historiador al no conocer con claridad el pasado. Sin embargo, al historiador lo caracteriza la curiosidad y asombro por descubrir lo que el brumoso paisaje esconde. Esta idea sobre la incertidumbre del pasado se diferencia de la hermenéutica de Gadamer $(1977,375)$, quien interpreta la cercanía abstracta del intérprete con los horizontes del pasado: "cuando nuestra conciencia histórica se desplaza hacia horizontes históricos esto no quiere decir que se traslade a mundos extraños, a los que nada vincula con el nuestro" (Gadamer 1977, 375), es decir, lo nuevo y lo viejo son parte de la misma tradición como único horizonte móvil. Por ende, ¿existe posibilidad de construir cercanía con la lejanía del pasado descrita por Gaddis? 
El rol del historiador está relacionado con el complejo entramado de los hechos históricos, ícono de la explicación histórica que nos permite discernir el pasado a través de un nexo significativo entre pasado y presente, lo que Gadamer (1977, 17) define como la universalidad del lenguaje. De esta manera, el conocimiento de mundos extraños es posible a través de la comunicación, donde el lenguaje es un mediador de la experiencia histórica a través de su uso y aplicación (Vásquez 1992,171-172). Lo anterior, complementa la idea de Gaddis respecto al extrañamiento del pasado ya que destaca el "entramado" acuñado por Hayden White, describiendo la libertad del historiador para manejar el tiempo y el espacio en sus narraciones históricas a través del uso de herramientas lingüísticas (Gaddis 2004, 40): tales entramados son nexos entre hechos históricos del pasado a partir de tensiones que desenmarañan la incierta neblina del pasado utilizando el lenguaje. De esta manera, el trabajo del historiador permite hacer comprensible el pasado para los lectores, generando una relación estrecha entre el presente y el pasado.

Estas ideas fueron parte del "giro lingüístico" que experimentaron las ciencias sociales en la década de 1970. Igualmente, de tal giro surgió la relevancia de la categoría de género y la significación de las relaciones de poder simbólicas entre sexos, estableciendo nuevos campos de estudio (Scott 2008, 59-77). La teoría del lenguaje develó el peso de un "lenguaje masculinista" que negó históricamente la posibilidad estructural y semántica de un género femenino (Butler 2007, 62). De esta manera, los estudios sobre mujeres han incorporado herramientas lingüísticas relevantes para rescatar la voz de las mujeres a través de las autobiografías y biografías (Castañeda 2010, 232-233). También, se ha escrito en primera persona con carácter personal y subjetivo, sin divorciarse de lo objetivo (Bartra 2010, 72). En relación con lo anterior, Scott $(1996,72)$ destaca que la historia de las mujeres ha invitado a reflexionar respecto a la objetividad de las normas disciplinarias imperantes: el dominio del pasado por los historiadores es necesariamente parcial. Por consiguiente, el estudio sobre mujeres integró nuevas categorías de análisis como el sexismo, la violencia sexual o política (Nash 2004, 170). La tarea de introducir a las mujeres en la historia exigió un cambio de conceptos respecto a las relaciones entre grupos sociales y modos de pensar la identidad colectiva de las mujeres (Scott 1996, 79). A su vez, señala Butler (2007, 46): "para la teoría feminista, el desarrollo de un lenguaje que represente de manera adecuada y completa a las mujeres ha sido necesario para promover su visibilidad política". Finalmente, la aparición de la historia de las mujeres en el campo historiográfico, con posterior apoyo de una categoría de género, ha permitido replantear el peso simbólico del lenguaje para pensar en soluciones presentes y construir espacios académicos democráticos que valoren el rol de la mujer en la historia. La hermenéutica ha contribuido en la reflexión sobre problemáticas asociadas a la valoración del rol femenino, es decir, el "lenguaje universal" ha permitido generar consciencia sobre cómo las categorías de "mujeres" y de "género" han pesado desde el pasado a nuestro presente.

La antropología, la crítica literaria y la filosofía han orientado las cuestiones contemporáneas al desarrollo lingüístico y metodológico de la nueva profesión de la historia (Smith 2003, 33). Especialmente, la metáfora fue esencial para realzar la comprensión del historiador con el pasado: por ejemplo, Gaddis utiliza el arte con la finalidad de esclarecer cómo el historiador desarrolla la creatividad de su pluma (Oviedo 2017, 215-216). Complementariamente, Gadamer señala que la metáfora es una puerta de entrada a la aplicación de una palabra en unidades vitales superiores, adquiriendo un nuevo significado (Gadamer 1992,173). La metáfora constituye un poder y la historia depende de 
ella en la comprensión de que algo se asemeja a otra cosa (Gaddis 2004, 18). Smith (2003, 32-33), desde el estudio de género, destaca cómo el pensamiento metafórico ayudó a los investigadores a progresar en sus carreras. Ello, se debe a que las metáforas facilitan la formulación de nuevas ideas, proporcionando un lenguaje en el que los científicos pueden reformular problemas (Smith 2003, 32 33). Por su parte, el "Punto de vista feminista" ha comprendido que el uso del lenguaje metafórico no le quita seriedad a un discurso que busca romper con los cánones tradicionales (Bartra 2010, 72-73). También, la metáfora ha contribuido al entendimiento de las relaciones desiguales y las luchas de mujeres frente a su histórica subestimación a partir del uso de las categorías de género (Tilly 1994, 61). Por lo tanto, el concepto de género es una vía efectiva para dar sentido a las relaciones entre lo femenino y lo masculino. También, es posible optar a la diversa índole de documentos como el arte, la música, archivos audiovisuales o fotográficos, los cuales constituyen una herramienta metafórica para darle un sentido superior a la realidad histórica y una representación al carácter de las relaciones de género, la figura y rol de las mujeres en la sociedad. Esto se puede ver a partir de la preocupación que adquiere lo visual al portar sentido más allá de lo descriptivo y relacionado con problemas inherentes a las relaciones sociales y su reproducción (Chow 1992, 101). Así, el uso de lo metafórico basado en documentos históricos visuales permite una mayor flexibilidad y complejidad al análisis histórico: desde tal herramienta metodológica el historiador puede adentrarse, a través de su investigación, a un viaje multitemporal, espacial y escalar. Ello, facilita el análisis de procesos históricos de avances y retrocesos sobre la lucha feminista y la institucionalización de la historia de las mujeres y de género. Por otro lado, el uso de la categoría de género ha contribuido al esclarecimiento de las problemáticas de mujeres respecto a las relaciones desiguales entre hombre y mujer.

\section{DEBATES HISTORIOGRÁFICOS Y ENFOQUES INTERDISCIPLINARES: Preponderando el rol de Las Mujeres en la Historia}

En el paisaje de la obra de Friedrich se observan distintos horizontes posibles en la lejanía que, bajo la vista de Gaddis $(2004,17)$, son de distintos tamaños al estar representados por montañas y llanuras. Esta idea se relaciona con la propuesta de Gadamer: los intérpretes están ubicados en un horizonte propio que los determina y que obedece a sus tradiciones. Desde ese punto, los intérpretes son capaces de comprenderse a sí mismo al encontrarse con el "tú", al cual deben prestar atención en la continuidad de la conversación para fundirse ambos horizontes (Gadamer 1998, 63; Gadamer 1977, 120-122). Cada horizonte, dentro de un diálogo entre dos entidades, es capaz de aportar su punto de vista a partir de un enriquecedor intercambio de palabras reglamentado por sus propias preconcepciones. Lo anterior, se puede representar a partir de la relación dialéctica entre la historia de las mujeres y el movimiento de mujeres, es decir, la teoría y la praxis: las historiadoras de mujeres se han parado frente a su homónimo como compañeras de lucha a partir de distintas posiciones. En tal situación, el movimiento feminista le ha otorgado potencialidad y sentido a la historia de las mujeres que, a su vez, al institucionalizarse y teorizarse, el conocimiento histórico ha reforzado el movimiento de mujeres a partir de su colectividad (Scott 1996, 75-80). Respecto lo anterior, Nash $(2004,175)$ señala que la dinámica de convertir la palabra en acción y la acción en palabra fue una de las aportaciones significativas del nuevo feminismo desde la década de 1970. 
A su vez, señala Scott $(1996,75-80)$ que los estudios de género han profundizado el carácter colectivo de la praxis y teoría de las mujeres a partir de la identificación de las diferentes experiencias de mujeres unidas en la lucha deconstructiva.

Por otro lado, las interpretaciones históricas son una representación de la realidad que pueden ser significadas a partir del lenguaje metafórico, simplificando el diálogo y el entendimiento entre diversas interpretaciones. Lo anterior, constituye el carácter fractal de la historia debido a que las interpretaciones históricas son diversas y existentes en lo confrontacional (Gaddis 2004, 117-118). Asimismo, existen interpretaciones abusivas o adecuadas. Es decir, dotar de sentido a una obra deviene de la dialéctica entre diversos puntos de vista, sino la interpretación resultaría dañina y de dudoso valor (Gadamer 1992, 107). Respecto a lo anterior, la ciencia histórica modernista se constituyó en torno a la idea de la verdad universal sin un análisis crítico del género y, al mismo tiempo, como una disciplina exclusiva para hombres (Smith 2003, 30). De tal manera, la categoría de género ha permitido comprender que la "dominación masculina" se ha degradado y develado como expresión de una relación social desigual (Dauphin 2001, 17). A partir de lo anterior, la historia de las mujeres y de género ha aportado novedad a la ciencia historiográfica contemporánea en la observación de fenómenos microestructurales, la construcción de identidades subjetivas y la simbolización de lo femenino a través de una relectura de las relaciones de género (García-Peña 2016). En conclusión, la categoría de género ha promovido debates respecto a las problemáticas que han develado en los estudios de mujeres la desigualdad de las relaciones de género. Tales debates han dado cuenta que no hay una verdad universal, idea que ha contribuido a la consciencia de evitar la preminencia de un género por sobre otro en el estudio del pasado.

En consecuencia, la valoración de la diferencia ha favorecido la comprensión ético-política de las desiguales relaciones entre lo femenino y lo masculino al alero del posestructuralismo y el posmodernismo. La posmodernidad significó la conjunción ecléctica de teorías que dieron cabida a temáticas de interés dispersas, conjuntadas y sin un hilo teórico claro (Vásquez 2011, 286; Ankersmit 2003, 191-199). Además, manifestó una predilección por lo trivial y lo marginal que permitió la diversidad de interpretaciones sobre un hecho histórico de manera horizontal a partir de nuevas interrogantes (Ankersmit 2003, 140-196). Lo anterior, ha permitido comprender la historia no sólo como una producción de conocimiento, sino también como una constante formulación de preguntas (Dauphin 2001, 8). De esta manera, a partir de la pluralización temática de la investigación histórica, las historiadoras de las mujeres pudieron referirse a la experiencia vivida por ellas mismas e integrar nuevos temas dignos de estudio relacionados con la casa y las familias, mostrando a las mujeres en distintas situaciones y funciones (Scott 1996, 75-76). La corriente posestructuralista, por su parte, se centró en el concepto ampliado del lenguaje y el discurso. También, mostró que la realidad es un producto constituido por un entrelazamiento de prácticas discursivas, poder y procesos cognoscitivos que, en su conjunto, determinan la realidad (Moebius 2012, 502). Además, estableció una práctica deconstruccionista que reveló lo excluido en oposiciones como hombre/mujer, naturaleza/cultura, interior/exterior (Moebius 2012, 497). 
Relacionado con lo anterior, Scott (1992, 87-88b) señala que el posestructuralismo fue una efectiva vía para pensar en términos de diversidades en lugar de una "teoría universal" ya que facilitó el análisis de las construcciones de significado y las relaciones de poder. Además, de la mano de un enfoque decolonial, la teoría feminista ha servido como un horizonte crítico para estudiar la invisibilidad de las mujeres como intelectuales: a partir de la relación categórica entre raza y género ha sido posible comprender la opresión de las mujeres subordinadas a partir de procesos de racialización, colonización, explotación capitalista y heterosexualismo (Dauphin 2001, 107). A partir de lo anterior, las vidas y obras de las mujeres han sido necesariamente una razón política repensando los sistemas de género (Scott 1996, 87-88). Antes de que la mujer fuera objeto relevante de estudio, se difundió una ciencia histórica que se enfocaba en la búsqueda de una verdad universal y, a su vez, era una disciplina especialmente para hombres (Smith 2003, 30). Posteriormente, cuando la historia se desarrolló en función del género, surgieron cuestionamientos sobre la formación académica de mujeres en universidades inglesas y estadounidenses en la década de 1970 (Smith 2003, 33). Sin embargo, no es la única vía para cuestionar tales tradiciones filosóficas occidentales: por ejemplo, las feministas posmodernistas han sostenido que la búsqueda de una sola visión de las mujeres es otra forma de pensamiento androcéntrico. Respecto a lo anterior, Blázquez (2010, 32-33) señala que las experiencias de mujeres difieren en edad, clase, etnia y cultura, lo que ha sido reprimido por el mito de la "verdad única". Desde tal óptica, Scott $(1996,80)$ señala que es difícil emplear el término mujeres sin pensar en las experiencias de las mujeres afrodescendientes, mujeres judías, mujeres lesbianas, mujeres trabajadoras, madres solteras, entre otras categorías. En definitiva, el valor que adquirió la diferencia de las interpretaciones contribuyó a la apreciación del rol de las mujeres en la historia y sus múltiples experiencias que, a su vez, conllevó a la complejidad de tales.

Desde la hermenéutica, comprender ya es interpretar: es la existencia humana misma desde la cual el historiador amplía la experiencia provechosa para la comprensión del presente y la sabiduría respecto del futuro con la mirada en el pasado (Gaddis 2004, 28; Gadamer 1992, 26-105). Tal interpretación encuentra su analogía en las imágenes fractales al encuentro de diversas interpretaciones y formas de comprender el pasado (Gaddis 2004, 115). De esta forma, la historia de las mujeres y de género se permitió salir del marco homogéneo de un discurso historiográfico cientificista y estructuralista. Esta perspectiva se adscribió a la nueva historia a partir de modos alternativos que rechazan la pretensión de verdad que inunda al mundo de los historiadores (Hernández 2004, 460). Es esencial hoy en día que la variedad de puntos de vista se despoje del fin de conocer la verdad como la última realidad en el mundo (Ruiz-Domènec 2017, 12). Este carácter liberador de la historiografía actual es aprovechado por la historia de las mujeres al reconocer la legitimidad de los prejuicios de otros horizontes. De tal dialéctica, constantemente emanan diversos puntos de vista sobre los problemas de género que afectan al presente y se proyectan desde el pasado. Tal situación le otorga flexibilidad y dinamismo a la historia, aportando nuevas respuestas sobre viejos problemas que surgieron del dinamismo del debate político.

Al estudiar Scott $(1993,434)$ el surgimiento de la mujer trabajadora en el siglo XIX explicó que no buscó legitimar lo que sucedió, sino cuestionar el pasado para abrir la historia a múltiples explicaciones e interpretaciones $y$, posteriormente, reflexiones sobre cómo podría concebirse hoy el trabajo femenino. Lo anterior, es un ejemplo del valor que ha adquirido la historiografía 
contemporánea, permitiendo el debate enriquecedor en la reflexión política actual al utilizar el pasado como un medio para espacios de discusión sobre problemas actuales. Esto, ha aportado nuevos conocimientos a partir de problemas históricos que posibilitan la construcción de sentido a partir de un enfoque interdisciplinario. A su vez, esta reflexión política define a la historia como una ciencia comprometida con el despojo de raíces modernistas que visibilizaron lo masculino en la producción de conocimiento. Por lo tanto, estudios de mujeres y de género aportarían en los espacios universitarios profundas reflexiones sobre el desdén del rol de la mujer en el devenir historiográfico. Lo anterior, pone a la historia como ciencia que aterriza a la realidad actual con propósitos políticos claros para otorgarle a la sociedad contemporánea un rol esencial educativo y ciudadano.

Discutir las interpretaciones del pasado es un acto de liberación de una explicación universal o única del pasado (Gaddis 2004, 183). La "verdad única", por lo tanto, ha sido parte de aquellas "interpretaciones abusivas" a las que se ha referido Gadamer $(1992,107)$. Estas son vías que permiten entender la redefinición de las nociones falogocéntricas del significado histórico a partir de su comprensión discursiva (Nash 2004, 26; Hernández 2004, 463). De esta manera, el pensamiento feminista, a partir de una dialéctica interdisciplinar con el pasado, sirvió como un marco y horizonte crítico para la comprensión de la invisibilidad de las mujeres con el fin de subvertir el silencio femenino desde el empoderamiento del sujeto subalterno (Nash 2004, 26; Oliveira 2018, 107). También, el uso transversal e interdisciplinario de la categoría de género ha sido útil para que los estudios de mujeres adquieran un poder crítico dentro del campo historiográfico (Dauphin 2001, 116). Por lo tanto, visibilizar el rol de las mujeres en la historia también fue un acto de liberación de las mujeres de un pasado en el cual se definieron erróneamente como entes inocuos.

Los horizontes no son cerrados, pues se entienden con otros horizontes y otras culturas. Por lo cual, el diálogo representado entre alteridades se define a través de la movilidad histórica de la existencia humana donde la razón del otro horizonte permite la autocomprensión del intérprete ubicado en la historicidad del lenguaje (Gadamer 1977, 375-377). El historiador está históricamente situado y, por lo tanto, dialoga con otras entidades. Esta apertura del horizonte, en relación histórica con otras miradas, define distintos puntos de vista desde los cuales los sujetos pueden estudiar el pasado. Este último aspecto, se asimila con los vientos que rodean al caminante sobre las nubes de la obra de Friedrich definidos por Gaddis $(2004,17)$ : las brisas que rondan al personaje principal de la obra representarían la conexión con el pasado a partir del círculo hermenéutico. Tales brisas portan la palabra que permite establecer la comunicación a través de un lenguaje en común.

La idea de la provechosa dialéctica entre alteridades de Gadamer y Gaddis se relaciona con el aporte de la interdisciplinariedad a los estudios de mujeres y de género. Lagunas $(1996,27)$ explicó que el diálogo de la historia con otras ciencias sociales posibilitó que la mujer emergiera en un contexto renovador e innovador para la ciencia histórica del siglo XX. Más tarde, Oliveira $(2018,116)$ señaló que el uso transversal e interdisciplinario de la categoría de género comprometería un alcance efectivo de su poder crítico dentro del campo historiográfico. Los estudios de alteridad inscritos dentro de la sociología y la antropología, en diálogo con la historia, han profundizado investigaciones deconstruccionistas que pusieron en jaque las formas comunes del pensar histórico (Hernández 2004, 141-458). Por tanto, en el ámbito de los estudios de mujeres y de género, de tal interdisciplinariedad resultan variedades de temas y 
escuelas que, según Scott $(2008,35)$, tienen una dimensión común correspondiente a sus esfuerzos por hacer de las mujeres el foco del cuestionamiento, el tema de la historia, un agente de la narrativa. En conclusión, el encuentro entre la historia y otras ciencias sociales ha permitido una proliferación de estudios de mujeres y género que han reclamado la tolerancia de lo subalterno. Lo anterior, ha sido posible a partir de las reflexiones en torno al lenguaje que, como se ha señalado anteriormente, otorgan un esquema de significados a la reproducción de las relaciones sociales.

\section{TEORÍA Y PRAXIS: EL DIÁLOGO ENTRE EL PASADO Y EL PRESENTE PARA LA PROYECCIÓN De LA Histórica LuCHA DE las Mujeres}

Gaddis $(2004,18-19)$ señala que los historiadores no tratan de predecir el futuro, sino que lo conocen a partir del pasado que se proyecta en él. Tal como el caminante ante un mar de niebla, el historiador avanza hacia el futuro con los ojos clavados en el pasado. Esto, refleja una relación estrecha entre el historiador con su pasado, empapado de un contexto histórico-cultural que conforma su presente. Esta idea encuentra similitud con la hermenéutica de Gadamer: el intérprete-historiador está en una constante mediación entre el pensamiento de su vida actual y del pasado a representar (De la Maza 2005, 132). Por lo tanto, Gaddis y Gadamer concuerdan con la idea de la proyección hacia el futuro, entendiendo la hermenéutica y el proceso de construcción de sentido por el historiador como un viaje hacia el pasado para entender el presente. De esta manera, es posible lograr una cuidadosa proyección hacia el futuro, aunque no sea el propósito primario del historiador (Petit 2018, 9).

La relación estrecha del historiador del presente con el pasado está dada a partir de la formación del horizonte de otra situación histórica necesitando del horizonte de su presente (Gadamer 1977, 376). Por ejemplo, Scott $(1996,84)$ señala que, a partir de la revisión de las contradicciones vividas por las mujeres del pasado, las mujeres investigadoras se sienten representadas en las desigualdades que también ellas han experimentado. Además, el intérprete, al comprenderse a sí mismo a través de la comprensión del otro horizonte, es en su existencia humana al darse en la no-determinación del futuro y a las propias representaciones (Gadamer 1998, 18). Esta relación del investigador del presente con su pasado en proyección sabia hacia el futuro se relaciona con el planteamiento de los desafíos propuestos por las intelectuales feministas al estudiar el pasado de las mujeres que dejaron huellas en el acontecer histórico. De lo anterior, Valobra $(2005,121-122)$ señala que el estudio de los movimientos de mujeres y grupos LGBTIQ+ adquiere el propósito de democratizar los espacios académicos y fragmentar el discurso hegemónico falogocéntrico, desvelando las singularidades identitarias. De tal manera, la historia de las mujeres se ha establecido como campo de estudio especializado que pone en duda la prioridad concedida a la historia masculina frente a la historia femenina (Scott 1996, 72). En relación con lo anterior, Nash $(2004,299)$ indica: "el futuro de las mujeres pasa por lanzar el diálogo y proceder a la construcción de una mirada de reconocimiento mutuo desde la diversidad de los senderos divergentes en el camino de sus derechos". Por ende, superar la subalternidad implica una mirada consciente del peso de las imposiciones históricas (Nash 2004, 299). En coherencia con lo anterior, la introducción de las categorías de género a los 
estudios sociales ha favorecido el posicionamiento de la lucha por los derechos civiles, los derechos humanos, la igualdad y el respeto (Pedro 2005, 78). Por ejemplo, para el caso de las mujeres lesbianas, la visibilidad del movimiento homosexual desafiaría las nociones predominantes y abriría a nuevas posibilidades para todos y todas (Scott 1992, 23a). También, relacionado a la idea anterior, Gayle Rubin $(2013,85)$, al estudiar la reproducción de las relaciones de género a través del estudio del "tráfico de mujeres", ha planteado que el movimiento feminista tiene que soñar con la eliminación de las sexualidades y los papeles sexuales obligatorios, construyendo una sociedad en que la anatomía sexual no tenga ninguna importancia para lo que uno es y hace. Finalmente, estas ideas definen la relación estrecha y única entre el pasado y el presente reflejado en el trabajo del historiador, aspecto que permite la comprensión de sí mismo al trabajar un documento. Tal relación, abre paso a la experiencia de la representación histórica, lo que posibilita mirar con sabiduría el futuro. De esta manera, los estudios de mujeres han contribuido a visibilizar la importancia del papel de la mujer en la historia a partir de la propia experiencia de las autoras. Esto ha permitido repensar su presente para delinear cuidadosamente planes a futuro que contribuyan a la construcción de espacios democráticos en las relaciones de género.

Según Gadamer (1977, 376-377), la conciencia histórica tiene su propia alteridad, encontrándose en un proceso constante de formación ya que el intérprete está constantemente poniendo a prueba todos los prejuicios con los que carga para conocer el pasado. De esta forma, el prejuicio no se impone, sino que se somete a una dialéctica compleja en el hilo conductor de la lingüisticidad durante esta "fusión de horizontes". Lo anterior, se relaciona con lo propuesto por Bartra (2010, 75): el "Punto de vista de las mujeres" no busca ser sordo frente al género masculino ni desarrollar investigaciones ginecocéntricas, sino desarrollar una ciencia sin géneros, mostrar a las mujeres y comprender de mejor manera el quehacer del hombre, quien no está solo en este planeta. En consecuencia, el despojo de los prejuicios del presente es el punto de partida para la comprensión del pasado y el diálogo sostenido con el presente para un análisis crítico de este último. De esta manera, el historiador no trabaja con la restitución del pasado; de lo contrario, se dedica a mediar entre el pensamiento del pasado y el de su contexto actual con el fin de comprender y darle sentido al otro horizonte (Petit 2018, 10; De la Maza 2005, 132). En este sentido, Gaddis $(2004,44)$ también difiere de la "no sobreimposición del discurso" ya que indica que el historiador, a través de su método, impone significado al pasado. Lo anterior, debido a que el sujeto del pasado no puede presentar su significado, contrariamente a la visión de Gadamer respecto al diálogo bilateral entre pasado y presente.

Por otro lado, Gaddis $(2004,24)$ refleja la flexibilidad de la representación histórica al mostrar que el historiador puede pasar del señorío a la humildad, sumergiéndose en el paisaje de la historia. Lo anterior, se relaciona con la óptica de Gadamer (1998, 100), quien indica que sumergirse en una obra permite construir sentido del pasado, sin abandonar los valores y preocupaciones del intérprete. No obstante, al mismo tiempo, el intérprete es consciente de una distancia con el pasado al reconocer cuáles son los prejuicios que porta al comprender aquel horizonte (Vásquez 1992, 173). Es decir, el historiador, durante el proceso de representación, también puede ser capaz de empequeñecerse para sumergirse en el vasto océano del pasado para desenmarañar las extrañezas de este. De esta manera, el historiador construye un entramado de los acontecimientos para otorgarles un sentido interrogando el 
pasado. Posteriormente, resulta un producto intelectual que debe ser expuesto al público para fines ético-políticos.

En conclusión, la construcción de sentido está dada por la dinámica de un presente vivo que es capaz de ir más allá de la exposición de un significado por parte de una entidad pasada. Este proceso es posible sin interferencia de la otredad del pasado, pero basándose en ella para mirar por las rendijas de los campos de indeterminación de una evidencia. De esta forma, la representación del pasado está determinada por un señorío del historiador al ser una entidad viva. No obstante, esta entidad vida también está encerrada en la prisión de la representación de un futuro, así como sus prisioneros del pasado. Por otro lado, este señorío podría estar representado por los métodos realistas de historiadores que buscan recrear el pasado sin optar a un cambio de paradigma que, para la actualidad, resulta urgente para liberar a los fantasmas del pasado a través de la libertad de interpretación en la relación entre el historiador y el lector.

\section{ENTRE EL SEÑORÍO Y LA HUMILDAD DEL HISTORIADOR FRENTE AL VASTO PAISAJE HISTÓRICO: EL DIÁLOGO HERMENÉUTICO FRENTE A LOS NUEVOS DESAFÍOS DEL ESTUdIO DE MUJERES}

Gaddis $(2004,34)$ explica que el historiador tiene el señorío respecto a este paisaje nuboso, debido a que el caminante se eleva sobre un paisaje distante, sin sumergirse en él. Este aspecto es entendido a partir de la metáfora de un sujeto a lo alto de una montaña que logra divisar la totalidad de un paisaje del cual, por tanto, obtiene poderío producto de su macrovisión del pasado (Oviedo 2017, 216). En cambio, las entidades que estuvieron implicadas dentro de los sucesos históricos, formaron parte del paisaje que los define como pequeños ante la vastedad del escenario. Desde este punto de vista hermenéutico, se observa en los estudios de mujeres cómo las investigadoras buscaron comprender el discurso hegemónico que relegó a las mujeres en su absoluto silencio para subvertirlo y darle otro significado a partir de su posicionamiento académico (Nash 2004, 26; Dauphin 2001, 108). Esto refleja cómo las historiadoras de las mujeres tuvieron la libertad de visibilizar a la mujer a través de sus herramientas metodológicas innovadoras y lecturas interdisciplinarias (Valobra 2005, 105). De esta manera, tales estudios pusieron en tela de juicio pautas profesionales que insistían en la inexistencia de la oposición entre teoría y política (Scott 1996, 69). Por tanto, el señorío de las historiadoras de las mujeres ha abierto el complejo camino de superar la subalternidad desafiando el androcentrismo y, también, ha salvado a las mujeres silenciadas de las ataduras de un pasado que subestimó sus acciones en la historia: mujeres, dueñas de casa, trabajadoras, pobladoras fueron importantes tejedoras del acontecer histórico.

Esta idea se diferencia de la visión de $\operatorname{Gadamer}(1977,377)$, quien señala que ambos horizontes encontrados en un diálogo entre lo nuevo y lo viejo crecen siempre juntos. Por ende, también existe una homogeneidad en la que ambos horizontes se dan históricamente (Vásquez 1992, 171). En la historiografía contemporánea, con el surgimiento de los estudios culturales, paulatinamente un número mayor de historiadoras ha obtenido mayor atribución sobre el análisis del pasado y ha incorporado con fuerzas el concepto de género con el fin de superar la incorporación de la mujer como un ente inactivo en el análisis histórico. Por ejemplo, Nash $(2004,298)$ destaca la importancia de la formación 
de las redes de apoyo entre mujeres activistas y académicas durante el desarrollo de la segunda ola feminista para resolver problemas asociados a la intimidad femenina tales como la violencia doméstica, el aborto o la discriminación lésbica. Flores $(2010,352)$, agrega que validar las acciones y los deseos de las mujeres en la historia es un puntapié inicial para el desarrollo de un proceso reconstructivo que "valorice su persona y constituya nuevas representaciones que favorezcan su capacidad de poder y autoestima". Esta valoración, desde el "Punto de vista feminista", ha permitido estudiar la acción de las mujeres del pasado con una mirada íntima, es decir, conectando con las emociones, gustos, talentos, preparación, ideología y la política del investigador (Bartra 2010, 71). Esto impacta en la escritura científica al inspirar emoción y cumplir, así, funciones psicológicas ante el lector (Smith 2003, 28). De esta manera, la humildad ha contribuido a la identificación consciente de las mujeres investigadoras con la lucha de mujeres a lo largo de la historia a partir de una compartida desigualdad. Esta identificación traspasa los límites de su pluma, despertando las emociones de los lectores y permitiendo una constante construcción de sentido sobre el pasado. Lo anterior, impulsa un mayor compromiso con la construcción de espacios democráticos no binarios en los círculos académicos a partir del estudio de las acciones de las mujeres del pasado.

Para lograr conectar con las emociones del pasado y, posteriormente, conectar con las emociones del lector, el historiador debe bucear en una memoria colectiva que recoja las experiencias de mujeres en los espacios públicos y privados (Dolores 2015, 231-232). La acción de bucear en la memoria colectiva de mujeres que han buscado reivindicar su acceso a la esfera pública, está relacionada directamente con la relevancia de sumergirse en la obra del pasado propuesta por la hermenéutica gadameriana (Gadamer 1998, 100). Este proceso hermenéutico permite a los estudios sobre mujeres y las relaciones de género, imbuirse en las experiencias femeninas pretéritas a través de una relación estrecha entre el pasado y el presente. Lo anterior, permitiría estudiar a las mujeres desde su individualidad y como parte de fenómenos amplios. De esta manera, los estudios de mujeres se insertan en la reformulación de la cientificidad de la nueva historia relacionada con la relevancia que se le otorga al juicio de valor en el escrito histórico para abarcar la experiencia personal. En relación con lo anterior, Delgado $(2010,204)$ indica que empezar por la experiencia personal es fundamental ya que permite que las mujeres se definan por sí mismas y valoren sus propias experiencias al destacar el papel de las mujeres en el pasado, resistiéndose a la cosificación. Esto, implica volver a la individualidad de un sujeto histórico reivindicado, mirado desde una óptica microscópica por el historiador a partir de la selección libre respecto de lo que considera importante. Lo anterior, debido a que el criterio selectivo permite, a su vez, estar en varios sitios al mismo tiempo para observar el funcionamiento de los procesos históricos, manipulando libremente el tiempo, el espacio y las escalas (Gaddis, 2004, 43-48). Es decir, la experiencia de cada mujer se conjuga con el movimiento global de mujeres, situación en la que el tiempo, el espacio y las escalas interactúan entre sí (Scott 1996, 61). Este aspecto se relaciona con la movilidad de los horizontes de Gadamer $(1977,375)$, entendiendo que la historia de las mujeres y de género se ha inscrito en la historiografía contemporánea a partir de la lectura crítica de las relaciones de género, evocando lo político y reivindicativo. A la luz de la historia social y cultural, el cuerpo femenino es una micro-óptica desde la cual el historiador analiza las dinámicas de poder en torno al género a partir de la variedad de escalas que aterrizan hacia temáticas relacionadas con la reclamación de los derechos de la mujer. De tal manera, las 
mujeres se observan oponiéndose férreamente a razonamientos que descalifican su rol como aquello insignificante para ser estudiado. Tales temáticas, requieren ser estudiadas bajo un lente bidireccional, donde el investigador sea capaz de inmiscuirse y concentrarse en las lecturas del pasado para proyectar en su presente la fusión de horizontes que enriquezca los debates políticos actuales.

Evocando el juicio de valor, es posible establecer una salida en la historia de las mujeres y de género para interpretar el pasado: la experiencia del presente puede otorgarles VOz, autoconciencia e identidad a las mujeres del pasado (Hernández 2004, 463). A su vez, las historiadoras pueden comprenderse a sí mismas a través de las pasiones y sufrimientos pretéritos de aquellas mujeres. De esta manera, el conocimiento de las mujeres puede aumentar constantemente, encontrando la estrategia para lograr incidir de manera significativa en el corazón de las diversas disciplinas y transformar su sesgo androcéntrico (Bartra 2010, 76). Lo anterior ha definido hermenéuticamente una relación simétrica o cercana, donde la intimidad del investigador se relaciona con los hechos pretéritos. Especialmente, las mujeres investigadoras se sienten identificadas con la causa feminista desde sus propias experiencias. Esto las hace sentir parte de una historia del movimiento de mujeres que está en constante construcción al buscar solidarizar con su causa a partir de la academia. Así, el estudio del pasado le entrega sentido al presente $y$, también, con tal significación es posible plantear desafíos y posibles soluciones a los problemas relacionados con la mujer y su visibilidad en lo público. De esta manera, la historia de las mujeres se ha instalado en el campo y trabajosamente va encontrando espacios en las universidades, centros e institutos de investigación (Valobra 2005, 120). Por consiguiente, resulta fundamental que los estudios de mujeres y género sean tratados desde una dimensión política pero también desde el compromiso social del historiador que avale la equidad social y muestre a la mujer como agente de cambio histórico y objeto de consideraciones políticas (García-Peña 2016; Hernández 2004, 462). También, resulta relevante el reconocimiento del género en la historiografía para refinar nuestro "espejo del pasado", reconociendo la naturaleza dialógica, múltiple e intensa del oficio de escribir el pasado (Smith 2003, 37-492). Identificar la presencia de las mujeres en los roles que les son propios ha resultado necesario para un retorno justo de las cosas y, así, nunca omitir su intervención y participación en el campo social, político y cultural (Dauphin 2001, 10-27). Finalmente, de tal reformulación intelectual de la ciencia historiográfica emergen estudios sobre mujeres con un carácter político, crítico y teórico que buscan construir espacios democráticos que valoren a las mujeres en su accionar como sujetos productores de cultura. 


\section{CONCLUSIONES}

En suma, la idea de la historia de Gaddis y la "fusión de horizontes" de Gadamer generan un complemento efectivo para dar salida al desarrollo historiográfico contemporáneo de la historia de las mujeres y de género bajo una perspectiva feminista. La perspectiva hermenéutica permite comprender cómo la historia de las mujeres y de las relaciones de género han surgido, bajo el giro cultural, a partir de su compromiso político con el movimiento de mujeres, tomando en cuenta la diversidad de experiencias de mujeres que surgen desde sus íntimas vivencias. Lo anterior, ha sido posible a partir de la introducción de las categorías de género, otorgándole profundidad y complejidad a tales campos de estudio. De esta manera, se puede observar cómo las relaciones desiguales de género actuales que ponen en duda la labor de las mujeres son producto de una larga tradición. Esta situación permite al investigador o investigadora bucear en la memoria colectiva de las mujeres para valorar la acción de mujeres del pasado como sujetos portadores de cultura en su conflictividad frente a la hegemonía varonil y, por otro lado, para dar respuesta a la visibilidad e inclusión de las mujeres en el espacio académico y/o profesional.

Para finalizar, el análisis de la perspectiva hermenéutica ha permitido generar consciencia sobre la escritura crítica de investigadoras que procuran rescatar a las mujeres del olvido como productoras de cultura. De tal análisis, el lector logra ser consciente de que la producción científica deviene de la cercanía de los investigadores con un pasado que contribuye a las reflexiones actuales respecto a las problemáticas de género. Tales ideas permiten definir a la historia como una ciencia comprometida con su presente. A partir de lo señalado, es posible proyectar el presente artículo a futuras investigaciones relacionadas, en primer lugar, con la contribución de la historia de las mujeres y de género al carácter ético-político actual de la ciencia histórica y, en segundo lugar, con los aportes de la hermenéutica de Gadamer y/o la idea de la historia de Gaddis a la epistemología de otras tendencias historiográficas actuales acordes al posmodernismo.

\section{BIBLIOGRAFÍA}

ANKERSMIT, Frank. Historia y tropología. Ascenso y caída de la metáfora. México D. F.: Fondo de Cultura Económica, 2003.

BARTRA, Eli. Acerca de la investigación y la metodología feminista. En: BLÁZQUEZ, Norma, FLORES, Fátima y RÍOS, Maribel (coords.). Investigación feminista. Epistemología, metodología y representaciones sociales. Coyoacán: Universidad Nacional Autónoma de México, 2010.

BLÁZQUEZ, Norma. Epistemología feminista: temas centrales. En: BLÁZQUEZ, Norma, FLORES, Fátima y RÍOS, Maribel (coords.). Investigación feminista. Epistemología, metodología y representaciones sociales. Coyoacán: Universidad Nacional Autónoma de México, 2010.

BUTLER, Judith. El género en disputa. El feminismo y la subversión de la identidad. Barcelona: Paidós, 2007.

CASTAÑEDA, Martha. Etnografía feminista. En: BLÁZQUEZ, Norma, FLORES, Fátima y RÍOS, Maribel (coords.). Investigación feminista. Epistemología, metodología y representaciones sociales. Coyoacán: Universidad Nacional Autónoma de México, 2010.

CHOW, Rey. Postmodern automatons. En: BUTLER, Judith y SCOTT, Joan (eds.). Feminists Theorize the Political. Nueva York: Routledge, 1992.

DAUPHIN, Cécile et al. A história das mulheres. Cultura e poder das mulheres: ensaio de historiografia. Gênero, Vol. 2, No. 1, pp. 7-30, 2001. 
DE LA MAZA, Mariano. Fundamentos de la filosofía hermenéutica: Heidegger y Gadamer. Teología y Vida, Vol. 46, pp. 122-138, 2005.

DELGADO, Gabriela. Conocerte en la acción y el intercambio. La investigación acción participativa. En: BLÁZQUEZ, Norma, FLORES, Fátima y RÍOS, Maribel (coords.). Investigación feminista. Epistemología, metodología y representaciones sociales. Coyoacán: Universidad Nacional Autónoma de México, 2010.

DOLORES, María. Historia de las mujeres y género. Una mirada a la época contemporánea. Revista de Historiografía, No. 22, pp. 211-233, 2015.

FLORES, Fátima. Representación social y género: una relación de sentido común. En: BLÁZQUEZ, Norma, FLORES, Fátima y RÍOS, Maribel (coords.). Investigación feminista. Epistemología, metodología y representaciones sociales. Coyoacán: Universidad Nacional Autónoma de México, 2010.

GADDIS, John. Elpaisaje de la historia. Cómo los historiadores representan el pasado. Barcelona: Anagrama, 2004.

GADAMER, Hans-George. El giro hermenéutico. Madrid: Cátedra, 1998.

GADAMER, Hans-Georg. Verdad y método I. Salamanca: Sígueme, 1977.

GADAMER, Hans-Georg. Verdad y método II. Salamanca: Sígueme, 1992.

GARCÍA-PEÑA, Ana. De la historia de las mujeres a la historia del género. Contribuciones desde Coatepec, No. 31, 2016.

HERNÁNDEZ, Elena. Tendencias historiográficas actuales. Madrid: Akal, 2004.

LAGUNAS, Cecilia. Historia y género. Algunas consideraciones sobre la historiografía feminista. La Aljaba, Vol. 1, pp. 27-33, 1996.

MOEBIUS, Stefan. Postestructuralismo y ciencias sociales. En: DE LA GARZA, Enrique y LEYVA, Gustavo (eds.). Tratado de metodología de las ciencias sociales: perspectivas actuales. México D. F.: Fondo de Cultura Económica, 2012.

OLIVEIRA, Maria da Gloria de. Os sons do silêncio: interpelações feministas decolonias à História da historiografia. História da Historiografia, Vol. 11, No. 28, pp. 104-140, 2018.

OVIEDO, David. Metodologías de acceso a la verdad en la reflexión históricocontemporánea: consideraciones a partir de John Gaddis. En: CORTI, Paola, WIDOW, José Luis y MORENO, Rodrigo (eds.). La verdad en la Historia: Inventio, creatio, imaginatio. Santiago: Ril, 2017.

PEDRO, Joana Maria. Traduzindo o debate: o uso da categoria gênero na pesquisa histórica. História, Vol. 24, No.1, pp. 77-98, 2005.

PETIT, David. La hermenéutica de Gadamer como fundamento teórico-filosófico de la historia conceptual en Reinhart Koselleck. Revista de la Academia, No. 25, pp. 27-42, 2018.

PHILAINEN, Kalle. La obra de historia. Constructivismo y politica del pasado. Santiago: Palinodia, 2019.

RÍOS, Maribel. Metodología de las ciencias sociales y perspectiva de género. En: BLÁZQUEZ, Norma, FLORES, Fátima y RÍOS, Maribel (coords.). Investigación feminista. Epistemología, metodología y representaciones sociales. Coyoacán: Universidad Nacional Autónoma de México, 2010.

RUBIN, Gayle. El tráfico de mujeres: notas sobre la "economía política” del sexo. En: LAMAS, Marta (comp.). El género: la construcción cultural de la diferencia sexual. Ciudad de México: Programa Universitario de Estudios de Género, 2013.

RUIZ-DOMÈNEC, José. Pensar la verdad de la Historia en el siglo XXI. En: CORTI, Paola, WIDOW, José Luis y MORENO, Rodrigo (eds.). La verdad en la Historia: Inventio, creatio, imaginatio. Santiago: Ril, 2017.

SCOT'T, Joan. Experience. En: BUTLER, Judith y SCOT'T, Joan (eds.). Feminists Theorize the Political. Nueva York: Routledge, 1992a.

SCOTT, Joan. Género e historia. México D. F.: Fondo de Cultura Económica, 2008.

SCOTT, Joan. Historia de las mujeres. En: BURKE, Peter (ed.). Formas de hacer Historia. Madrid: Alianza Editorial, 1996.

SCOTT, Joan. Igualdad versus diferencia: los usos de la teoría postestructuralista. Debate Feminista, Vol. 5, pp. 87-107, 1992b.

SCOT'T, Joan. La mujer trabajadora en el siglo XIX. En: FRAISSE, Geneviève y PERROT, Michelle (eds.). Historia de las mujeres en Occidente. Vol. 4: El siglo XIX. Madrid: Taurus, 1993.

SCOTT, Joan. Os usos e abusos do gênero. Projeto História, No. 45, pp. 327-351, 2012.

SMITH, Bonnie. Gênero e História: homens, mulheres e a prática histórica. Bauru: EDUSC, 2003. 
TILLY, Louise. Gênero, história das mulheres e história social. Cadernos Pagu, No. 3, pp. 29-62, 1994.

VALOBRA, Adriana María. Algunas consideraciones acerca de la historia de las mujeres y género en Argentina. Nuevo Topo, No. 1, pp. 101-122, 2005.

VÁSQUEZ, Adolfo. La posmodernidad. Nuevo régimen de verdad, violencia metafísica y fin de los metarrelatos. Nómadas, No. 29, pp. 285-300, 2011.

VÁSQUEZ, Francisco. La transformación contemporánea de la hermenéutica y el estatuto epistemológico de la Historia. Fragmentos de Filosofía, Sevilla, No. 2, pp. 165 184, 1992.

La "fusión de horizontes" de Gadamer para la historia de las mujeres y de Género con base en la noción de la Historia de John Gaddis Artigo recebido em 01/09/2020 • Aceito em 20/04/2021

DOI | doi.org/10.5216/rth.v24i1.65420

Revista de Teoria da História | issn 2175-5892

(c)

Este é um artigo de acesso livre distribuído nos termos da licença Creative Commons Attribution, que permite uso irrestrito, distribuição e reprodução em qualquer meio, desde que o trabalho original seja citado de modo apropriado 